\title{
THE PUBLIC ADMINISTRATION TRAINING RESEARCH PROJECT
}

\section{Bernard Schaffer*}

Training is a fundamental part of recruitment, appointment and personnel movements. There have always been two different, though not necessarily opposed, approaches to training: apprenticeship, on the job, with a master (experienced and superior): or off the job, with teachers, probably in a more or less separate ad hoc and formal setting. The Dialogus de Scaccario represented one approach; Plato's guardians were to be prepared by the other. The United Kingdom has tended to use the former, education being regarded as preliminary rather than preparatory. Napoleonic France, with its écoles for the grands corps, and Prussia, with its cameralist universities, used the latter.

Training is also related to status and hierarchy. Insofar as training is done through apprenticeship, it promotes stability and reiteration. The alternative method, through institutional arrangements, in European civil services and elsewhere, was intended for élites. Institutions for élite entry were one of the ways in which elites were united and kept distinct both within and outside their arenas.

Ironically, there was nothing in the history of training, particularly in public employment and education, to suggest this as a source of radical change and reform. Furthermore, British administration at home had had no experience at all until recent times of training, and until very recent times indeed of administrative training. Yet, it was against this background that newly independent countries had to turn to training, and institutional training at that, as a way through the problems which faced them, and to draw on what appeared to be expert advice. This is not the place to rehearse again that particular story, which we have now told (Zoe Allen, in B.B. Schaffer ed., Administrative Training and Development, 1974). What has to be done is to say that we learned from our examination of that story and its outcomes.

\footnotetext{
*Bernard Schaffer is a Fellow of the Institute.
} 
The public administration training research project began out of some conversations between Colin Leys and myself in the summer of 1967. We were comparing what we had assumed would be our very different experiences of administrative training in East Africa in the one case, and in the Pacific in the other. We found to our interest that, while the experiences were distinct, they were not at all without similarity, and provided many points of comparison. This led us to decide to recruit resources and people, and work out methods to research those training programmes offered in institutes which had been set up specifically for members or potential members of the higher levels of the public services. What we wanted to see was why both in the period of preparation for independence, and in the ensuing periods, there was always such an investment of technical assistance and domestic resources, economic and political, in the institutionalised training programmes. Why did investment go on; what sort of sense did it make? Why had there been crash programmes of localised training?

Work began in January 1968 with the arrival of Theo Mars as research assistant. It was to be a three year project, ending in 1971 . Provisional reports were made at the end of 1968 and 1969 to ODM, which provided the core, though not the total finance throughout. A concluding summary report was made on 9 March 1971 (B.B. Schaffer, Institutes for Administrative Training in Developing Countries, 1971).

The project basically consisted of three phases with certain overlaps; first, the design of a common research manual, second, the operation of the manual in selected field situations, and third, the writing-up of the material and production of reports. We were assisted in various ways by a great variety of people including the principals and members of the several institutes studied, and people to whom they were responsible. David Chenoweth, then principal of the Administrative College and now a member of the Public Service Board in Port Moresby, helped us greatly at the beginning. And so both at the beginning and the end did Jake Jacobs; Robert Parker of the Australian National University, and many others, most notably perhaps Ralph Braibanti, with whom I was able to discuss the project before returning to the UK from the USA at the beginning of 1968. 
The preparation of the research manual taught us a good deal about administrative theory and some problems of evaluation. The manual is deposited in the IDS Library. A good deal of work was done on the secondary literature by Theo Mars in the IIAS Library in Brussels, and by Zoe Allen (now Zoe Mars) who organised the relevant chapter. Some field research was done by David Chenoweth in Northern Nigeria. The basic fieldwork was done by Colin Leys in Kenya, Patricia Stamp on the East African Staff College, Geoff Wood on the National Institute of Public Administration in Lahore and Theo Mars on the National Academy of Administration in Mussoorie, near Delhi. We got certain other primary material from the Philippines and Papua New Guinea. We were involved in a comparative study of what we might call the British case, the extremely interesting decision-making situation which produced, at last, profound changes in administrative training for the UK home civil service in the 1960s. This was done by Gabriel Iglesias.

Apart from the reports to ODM, and from ad hoc reports to the host institutions, which tended to be done while the fieldwork was actually in process, there has been a wide variety of other outputs, as indeed there was a wide variety of support, not only from the ODM, but also from the Social Science Research Council, the Canada Council and the Ford Foundation. Outputs include Colin Ley's chapter "Recruitment, Promotion and Training" in G. Hyden and other eds., Development Administration - the Kenya Experience, Nairobi, 1970, and his article on "The Internal Evaluation of Administrative Training: Some Practical Aspects", African Administrative Studies, vol. 5, 1970. Colin Leys and Patricia Stamp completed an as yet unpublished manuscript called "Organisation and Development: Dilemmas of Administrative Training in Kenya". Iglesias, Cabatoff and Wood all completed successfully their university theses. Evidence was given, particularly in Kenya by Colin Leys, to both the Wamalwa and Ndegwa enquiries, and in each case was incorporated substantially in the final reports. I was able to report about the work to various conferences and gatherings, like the Round Table on institutes of public administration and administrative development in the Arab world, in February 1972, (B.B. Schaffer, The Problems of Using Training in Administrative Development, and Problem Alternatives, 1972), or the Fourth 
Waigani Seminar, (B.B. Schaffer, 1970). The approach developed in the work has been applied on other occasions, as by Jacobs and Schaffer in our Swaziland report of this year, and in the evidence we gave again this year to the Commonweal th Secretariat in its discussion of a possible Commonweal th Training Institute. Some of the more general conclusions about policy decisions and institutional evaluation were put by me in an IDS Discussion Paper (Schaffer, 1973) and in a forthcoming article in Development and Change, (Schaffer, 1974b).

The first point was not just that we were looking at training, but training in particular times and places and done in a special way, that is to say, through institutions and not through apprenticeship. The evaluation of this sort of training meant the evaluation of training institutions. We thought we would learn here the importance of the distinction between what we called sophisticated and primitive evaluation of administrative processes. But that was not the important thing which we learned at all.

What we did find was a distinction between what we came to call "official" and "authoritative" evaluation. "Official evaluation" means those evaluation processes, either sophisticated or primitive, which remain in institutional hands. They become part of the institutional game, and include the reiterated pretence that evaluation of manifest administrative inputs and outputs cannot be done. "Authoritative evaluation", on the contrary, means evaluation done by others, not within institutional control, and according to processes having enough objectivity to enforce respect. There are moments when such evaluations may well and sometimes do occur, and the notion of there being "evaluation moments" of this sort was, we thought, an important finding if we could work out ways in which authoritative evaluation could be described, the moments recognised and the possibilities implemented.

We found that training institutes were peculiarly adept at the employment of official evaluation, that is, evaluation processes held more or less exclusively in their own hands. Training is a field where the possibility of any evaluation of the manifest processes (of this sort of administrative action) is peculiarly susceptible to challenge. 
Hence the continual stress placed on what are called "latent outputs" of training. At the same time, training institutes always say they want to do more research, and they do have moments when they have to be open to outside influences. At those evaluative moments, authoritative evaluation can occur if a methodology is established, and this was one of the things we were concerned about, and one of the areas where we made certain findings.

Along with this went the finding of how different were the points of view of the various participants in institutional training programmes. This was so in the routine phases which lead to the persistence of an institution, like its budget, its programme, its recruitment for courses and so on. If training is to be done through institutions, then the institutions will have to persist. Much institutional maintenance is in fact routine. In routines of institutional life, there are many differences in points of view, perhaps particularly in what we called the "training relationship". Differences in views are also very clear when the issue is whether an institute should be set up. Both in such routine and in such crucial occasions the different views can provide the possibilities for authoritative evaluation. This may be so also at critical moments when the training institute is preparing to adapt its programmes to divert attention away from the more fundamental question as to whether the institution should survive at all.

In all such phases, crucial, critical or routine, there will be present, we found, a very powerful institutional ideology. Successive phases of participation, or discussion of crucial issues like the creation of training institutes, have seen the appearance of ideologies, such as maintaining standards, or management transfer, or institution building. There were also moments in such situations when some of the participants were somewhat desperately searching for ideological positions, and a sense of vacuum tended to occur.

The vacuum could always be filled, and the evaluative moment always resisted, because there would always seem to be a "training need". We will say more about this problem of needs and goals and the elliptical leap taken to actually set up institutes. In the meantime, we noted that there were several ironies about the creation of training institutes. In the first place it was true that the 
French public services did have a great deal of experience of institutional training, particularly with the creation of the Ecole Nationale d'Administration after the war. This provided the services in francophonic countries, through powerful processes of technical assistance, with a single clear model. There was no such model and no such experience in Britain. Yet anglophonic territories were at least as enthusiastic about institutional training as the francophonic countries.

Secondly, and more importantly, we discovered a fundamental difference between two sorts of institutional training. On the one hand there was an institutional programme which was an essential gateway to much competed-for élite levels or cadres in more or less hierarchical public services. The Academy in Mussoorie was a clear case in point. On the other hand, there was the institute and programme whose job was seen to be remedial or innovative for mid-career civil servants. When new public services had to be created overnight there was no alternative to the use of institutes for crash localisation programmes. The Institute of Public Administration, which was set up in Zaria, in Northern Nigeria, was a clear case. When that phase passed, other jobs had to be done if the institutes were to be justified. There was nothing particularly developmental in the first or élite cadre type of institution. It was the second, remedial or innovative type which was seen to be developmental. It was, however, the first which was successful, and the second which had all the difficulties. (The transition in Britain from the Centre for Administrative Services to the present Civil Service College provided in fact much the same sort of picture). If institutes are to be justified outside the context of crash localisation and preparation for élite cadre positions, quite different approaches to training were required from what had been provided by the traditional concept of training institutes (standards, transfer and institution building), with all the mimetic effect of technical assistance.

The difficulties of the remedial institution indicated both where the problems were and where the alternative processes, both of authoritative evaluation and of training performances, might lie. Difficulties were encountered in student release, the motivation of the trainees, the relationship between the trainer and the trainee, the 
link between the institution and the public service job. Institutes had been launched at other times and with other interests, generally with great initial réclame. But the initial interests, including the technical assistance components, often departed, and the later phases of institutional maintenance, routine and persistence were very different. This frequently forced them either down to a low level of performance or to a heavy reliance on training networks for their maintenance. This suggested that the initial statements of training needs from the point of view of this interest or that, the opening statement of goals, a general perception that a public service has problems (as which does not) was in no sense an adequate basis for justifying the creation or maintenance of an institution and not a necessary basis at all for processes of evalutation. Evaluation could rather, in fact, be based precisely on those difficult or sensitive matters: trainer-trainee relationship, success or difficulty in trainee recruitment, linkages between institution and public service, a follow-up from training session to job.

Furthermore, as the 1960s passed, the decade could be seen as having assumed an attitude to institutional training which would probably not be maintained. The failure of the industrial training boards in the UK was a case in point. More fundamentally there was an attack on institutional training as such, and particularly on the remedial or innovative process. This was partly perhaps because the context had changed, partly because the distinction between the cadre and remedial institution was more clearly seen, partly because many alternatives, such as business schools emerged. The older style of management or staff college type of institute was now in a difficult position. Bluntly, if the job was changed, mid-career remedial institutional training had simply not made its case as an instrument of innovation. Indeed, all our work showed that "a man may well learn to talk about taking action simply by talking about taking action (as in classes at a business school), but to learn to take action (as something distinct from learning to talk about taking action), then he needs to take action (rather than talk about taking action) and see the effect, not of talking about taking action (at which he may appear competent), but of taking the action itself (at which he may fall somewhat short of competence)." (Revans, Developing Effective Managers, 1971). 
This did not mean that training institutes were to be rejected on the ground, forthwith, in all cases. In the first place, the French model obviously worked very well. In the second place, so did élite cadre institutions in anglophonic situations, provided of course that élite cadres remained also. In the third place, administrative training institutions proved to be adept not merely at carrying out processes of official evaluation, but also at critical adaptations which not merely made their persistence possible, despite phases of political and ideological change, but also consisted of making the best of their difficulties; (the East African Staff College, for example, made a merit out of its lack of a permanent base).

We discovered that it was a much better guide to what was going on in the world of institutional administrative training, a better approach to evaluation in fact, not to look at the initial statements of needs and goals. They told us very little about what was happening or what could happen. The important thing was to look at the ways in which the training institutes dealt with the awkward evaluative moments. Once a training institute has been set up, at any rate an institute of the remedial sort, it seems to suffer from an inevitable drift away from its own public service, an inevitable erosion of its original status. This could be recognised. It would also sometimes be dealt with by an institute, either through making something of a strength of it, or through positive efforts to reverse the trend by building up new programmes, new functions of research and consultancy, etc. This suggested that evaluation should be done by looking at how these moments are dealt with, and not by looking at initial statements of needs and goals. It suggested too, what some of the conditions of a worthwhile plan for a remedial training institution should be. These would have to include certain things about its context and certain things about its programmes. As far as its context was concerned, this would have to include the sort of public service it was working for. It made no sense at all to attempt to build a training institute of this sort, to discuss its setting up, or to think about its programmes, irrespective of the degree to which the service was an élite dominated service, or of some less hierarchical sort, and indeed what sort of élite it had: single or multi-service, generalist or specialist, etc. There would be a close relationship between the more or less hierarchical nature of the service for 
example, and the training apparatus which it possessed. The apparatus might be dependent on the hierarchy; and if there was going to be an effort to do something about hierarchy the role of the training apparatus could be crucial.

It was not just a matter of context to which we were directed: it was quite clear that there were certain conditions which marked the more successful remedial training programmes. The programmes, for example, had to be mixed with effective research and consultancy activities, indeed virtually made a product of them, as in some Egyptian and Iraqi examples. In the second place, the professionalisation of the training career seemed to be a disadvantage. Furthermore, it was perfectly possible to do much more non-primitive evaluation of training activities, than maintained by the extreme exponents of the latency argument (that training only shows its outputs in the long run; that in the long run it will always be seen to have been worthwhile; and that if a particular programme did not do what it said it was going to do, it nevertheless would be seen to have done something equally or more worthwhile). Some quite simple quantitative studies, for example, would show whether some parts of the training programme, field trips for instance, had been meaningful. (Cabatoff did this for Lahore very well).

So we found that there were ways in which a methodology could be built up for authoritative evaluation at least of administrative training institutes of these sorts. We found comparabilities between very different situations. We also found a degree of reiterated behaviour, like the difficulties of the training relationships or of fieldwork in remedial training institutions. The paradigm was the difference at the National Academy in Mussoorie between the foundation and the refresher courses, and in the relationships between the probationers and the "Director's staff" on the one hand and the academics or "professors" on the other.

Some of our results were of more strictly academic interest. These related partly to the revealed possibilities of comparison between such different situations as were represented by these widely scattered institutes. What was meant by comparability was not 
similarity, though there were indeed certain similarities, such as a tendency to loss of status, a weakness in research records and the problem of getting political direction, the problem of adapting from the crash localisation to later phases, the roles played by technical assistance and so forth. Comparison could be made, we found, by posing certain conceptual questions, relating, for instance, to the ways in which institutionalisation processes were occurring. What we meant by institutionalisation was what had been classically defined in the work of Parsons, Starbuck, Sills, Merton and others, applied to educational institutions by Burton Clark, and defended by Huntingdon. Institutionalisation was, "the way in which situations in which exchanges are occurring, develop procedures and practices like rights of entry of participation, or rules for success and failure, which acquire a value in themselves and hence a peculiar stability. Such situations thus become more complex, more self-sufficient and self-sustaining, more coherent and so more adaptable as they face challenges from outside. Institutionalisation is about the values of participants. It affects their actions, choices and decisions. The more that happens, the more the situations are likely to survive". In fact, "institutionalisation means that people in a situation come to decide more and more that it is worthwhile keeping that situation going, despite what may be happening to its manifest goals around which it was brought together". (Schaffer, 1974, chapter 7).

Comparison could be done, and certain concepts like institutionalisation seemed to be especially useful. But this was not only an academic matter; if a comparative methodology, particularly of institutional evaluation, could be built up, we were getting to the heart of our task. What we found was that there were certain lines which institutionalisation in training situations seemed particularly prone to follow. In the first place, it was shown to be both necessary and possible for training institutes to go through adaptation and goal changes so as to survive. This was not merely a matter of moving from crash localisation to later phases, or initially high to lower levels of support. It was also frequently a matter of making a virtue out of necessity, as with the East African Staff College, already mentioned. Secondly, training institutes are particularly adept at creating institutional language, so as to take the danger out of their trickier linkages and operations, to send out signals and to disguise 
the more sensitive relationships. The best known of these forms of institutional language is no doubt the way in which the students or trainees in the training institutes are almost always described by other terms (e.g. participants, members, study fellows). Thirdly, there was the process which we called the "comparability game". This was a matter of gaining strength and territory, insulation from attack, and in effect support for positions occupied by a combined process of comparison with favoured, and distinction from unfavoured, alternatives. "Sometimes it seems to be useful to an institutional leader to say that his institution should be supported because it is like some other. This staff college existing or being proposed is like that staff college, this piece of training is like that piece of army or American training. Sometimes the point may be to establish difference. Institution $X$ should be maintained because it is distinct from Academy Y and College Z”. (Schaffer, 1974, p. 38).

Training institutes emerged as places where the leap from objectives and goals, from a general perception of "problems" to a programme, from "training needs" to the specific decision to set up a training institute was particularly easily taken. This was done without any evaluation of the distinction between these perceptions and the commitment to the maintenance and routine performance of a training institute. It was also done without evaluation of the difference between what was seen as a problem (the need for public service reform in general) and the particular outputs which the training institute was supposed to achieve or was actually achieving.

This leap was taken the more easily because of the operation of the training network. "A training network is the not wholly self-conscious structures through which those concerned with the creation and maintenance of institutions are assisted in playing the game of comparability". There were the exchanges through technical assistance, the national networks of administration, and then the training network itself, though not all trainers were members of the training network. The training network also explained something about what we detected as "the incremental 'escalation' of training institues" (Schaffer, 1974, pp. 38-39). 
We had to explain how training institutes seemed to produce more training institutes, the solution for training seemed always to be more training, and meetings by leaders of training institutes seemed always to necessitate more meetings by leaders of training institutes. The elliptical leap was always possible, the training needs argument was always deployed, the costs were always more or less hidden. Where they came out powerfully into the open, as with the industrial training boards in the UK, the institutionalisation of training suffered severely.

Other characteristics of training institutionalisation went with these difficulties for authoritative as against official evaluation; the deployment of the training needs ideology, the comparability game, and the disguise of sensitive relationships like recruitment and the training relationship itself. We have referred to the misplaced professionalisation of the training career, and the characteristic ways in which arguments about latent outputs could always be deployed in evaluation sessions.

These analyses of the institutionalisation processes in training situations did more than reinforce in our minds the need for developing a methodology for institutional evaluation as part of technical assistance and administrative planning, etc. They actually suggested how authoritative evaluation could be approached: in particular by building up a typology of institutional training situations (like the difference between the cadre and remedial institutes). There would also be a check-list of institutional behaviour worth looking for (the training needs argument, the comparability game, the network, incremental escalation, etc.), and the evaluative moments which were likely to occur at sensitive points in the training relationships (recruitment, fieldwork, job placement, etc.). This was the most noticeable in the past in the changeover from crash localisation to that second generation or middle age of organisations which Robin Luckham has elsewhere so brilliantly described. (R. Luckham, The Nigerian Military, 1971).

It must be stressed that there are differences in the ways in which various categories of participants behave in situations leading either to the creation or to the persistence of training institutes, and the 
sorts of interests they have. Yet in a technical assistance or public administration agency concerned with these sorts of questions, there will be those who really need to put questions other than mere statements of open-ended training needs or latent outputs in the end. This is where authoritative evaluation of institutional performance ought to become possible. Certainly the Wamalwa Committee in Kenya (with our help) did put these questions. The Fulton transition from the Centre for Administrative Services to the Civil Service College did not. Furthermore, if our argument stands that on the whole, training institutes work well in élite cadre situations and badly in remedial innovative situations, then the role they can play in the present phase of major administrative reform becomes much clearer - or the questions to be put about them do.

There are two points which emerged here. The first was that training institutes on their records were very good for some things, but not good at all as instruments for major administrative reform, particularly in isolation. Yet they were often (not to say, always) put forward in precisely that guise. The training needs argument rested on the view that the public service did have problems; there was a need for reform; this was a training need and an institute should be set up to fulfil it. I have seen that argument time and time again: it is highly defective.

The second point is that administrative reform needs to have a more precise agenda, for example, improving decision-making processes and techniques, providing some alternatives or corrections to extreme versions of élite, hierarchical and unequal public service systems, and improving methods of decentralisation, area planning, participation and "across the counter" or access relationships. If training institutes were to play a role in such an agenda they were going to be quite different either from élite cadre institutes, by definition, or from crash localisation. The whole tenor of the argument strengthened the implication of the findings of Revans and ourselves that what was actually needed was changes in jobs and performance, in action in fact. What contributions could the resources of training institutes make to such changes? The answer was that institutes could become bases for policy conferences, research, consultancy, on the job supervision, technical exercises and village 
programmes. This answer was inconvenient for many existing institutes; it was also very different from what official evaluation would produce.

The point then was that very different contributions were needed in this second generation or middle age of training institutes from the mimesis, ritual and élite reinforcement which made up some of the present contributions. What chances were there of getting such fresh contributions? The answer which followed from our work was that it depended on exploiting the possibilities of the evaluative moment. This meant creating fresh decision-making situations, in which people with different interests, information and decisional processes from members of the training network (who would tend to dominate the technical assistance processes) and representatives of the training institutes (directors, administrators, and professional trainers) would be present.

Of course this was difficult. It meant recognising that training was not just the work of institutes: not merely that institutes themselves could make different types of contribution, but also that training was part of the process of staff development. This in its turn carried implications for processes of administrative reform, public service departments and establishments, authorities, etc. It also meant recognising the existence of evaluative moments, anticipating them and building them into the new decision-making structures. For example, the end of a training course is usually the worst moment for authoritative evaluation. The better moments are those when training relationships are at their most sensitive, when there are crucial possibilities, like changes in the political context, when there are actual challenges to the institute's territory, and when the costs of training are at their most evident.

Two main practical points follow. The first is that proposals for training and a training institute should be based not on statements of training needs and of the goals or objectives of training programmes, but on a training plan which would attempt to indicate or anticipate these evaluative moments. The second is that the training plan should, above all, indicate the linkages which are going to be built up. Around these linkages revolve the real likelihoods of what the 
training outputs will be. It is also round these linkages that authoritative evaluation is most likely to occur. We need to be told, for example, what sorts of guarantees there are in relation to trainee recruitment and to post-course placement. We need to be told what sort of a training institute is going to be created here: cadre, remedial, or something else. We found it was just this sort of anticipation of the possibilities of authoritative evaluation which were most frequently absent from the discussion of training programmes.

It was, then, training linkages which should be used to provide bases for authoritative evaluation, and which should feature most strongly in the training plans which we saw as necessary, bearing in mind the different sorts of training institutes which could be set up. This was a matter of training linkages, not of training needs. Training needs would always be available, they did not deal with the leap from problems to performance, and they did not distinguish between needs. What became clear to us in our researches was the way in which institutionalisation dominates policies, decisions, and evaluation. Briefly, policy decisions seemed to be taken by institutions (technical assistance agencies, training institutes, establishments, departments, etc.) so as to lead to more institutions or the maintenance of those which already existed. Against that domination it seemed necessary to be able to analyse and evaluate them, to distinguish, for example, between their initiation and their maintenance. Training institutes on their record were very good at keeping their programmes going and at adapting their programmes so as to keep themselves going. Hence our distinction between the routine, the critical and the crucial, which we formulated as a further useful element in the institutional evaluation methodology we were trying to establish.

What we found as a result of the researches was that evaluative moments could be distinguished, and a methodology of institutional evaluation applied if it were available, and if there were those who were prepared to apply it. This did not mean that we were arguing that the overall record of training institutes was negative, but that it was very different from what was implied by statements of goals, of overall problems of training needs and of intended 
outcomes. Yet there were situations like cadre recruitment and crash localisation, policy conferences and preparation for specific tasks like the operation of elections, or the teaching of accountancy techniques to middle executive and local government levels, etc., where the record was good. It simply differed from the implications of many of the technical assistance, transfer of technology, institution building, administrative development, administrative reform and innovative types of argument. Furthermore, the capacity of the institutes to avoid crucial issues about their persistence to keep going, in fact, was obstructing those potential policy decision situations in which wider views of training and staff development should have been considered, particularly as public services moved forward to situations in which the implementation of localisation was to be taken much further. This is the dominant present phase for development administration. If the 1960s was a decade for medium-term national aggregate planning, it was also a phase in which development administration looked to institutional training processes, particularly for preparatory, transitional and crash localisation jobs.

In brief, we have surveyed that astonishing phase in political and administrative development which saw the achievement of independence and the creation of new states, and saw as part of that not merely an enormous growth of administrative training institutes, indeed in effect their invention, particularly in anglophonic areas, but also saw enormous reliance placed on them. This was expressed in relation to many hopes, varying from the avoidance of chaos and disaster to the creation of viable new systems. So much, as it were, was entrusted to so little. But many interests expressed themselves here: the interests of the colonial masters at one stage through technical assistance agencies, the training networks, and many others. Indeed, the strength of the training institute movement was partly that training seemed to suit so many and challenge so few: perhaps all too many and all too few.

The second point is that there were distinctions to be drawn between one and another sort of institute and one and another sort of phase through which the training institute movement passed. There was also a distinction to be drawn between the different interests 
present: what the agencies, the networks, the civil service, and others each wanted was highly distinct. In some situations, the outcome was to be a new training institute and programme (with or without technical assistance participation). In others, the issue was the routinisation of the programme and its performance, its linkages, its training relationships and its output, and the way in which the institute would deal with challenges to its programmes and even to its continued existence. What was quite clear was that there ought to have been present in each of these distinct situations some participants with an interest in authoritative evaluation, and with the methodology to make it possible.

Significant changes are now affecting some of those interests which fathered the training institutes, including technical assistance agencies, and the panoply of devices which such interests tended to deploy. The focus has moved to schemes of service, to the use of management service units and to hopes being placed in major administrative reform and its strategies rather than in training institutes. The official history might run thus: the services have been localised and created; they have been trained, and now it is time to reform them. In part, as with the training institute movement itself, these changes contain real concerns and genuine possibilities, a movement away from institutional training to training on the job, from the trainer-teacher to the trainer as supervisor, and from training as programmes to training as part of staff development. But once again there are powerful trends of interest and institutionalisation at work. As with the training institutes, so here too the contribution of research and enquiry must in part be to assist in developing a methodology of institutional evaluation, and to support those processes and moments where the methodology might be brought to bear.

The work of the public administration training research project does provide a contribution and an approach in the present phase. This is partly a matter of recognising that the work of training institutes continues, and that the use of institutes is still seen to be a major part of the agenda of schemes of service, management service units and administrative reform. Further steps in the methodology of institutional evaluation need to be taken. We must recognise in our 
experience that there are peculiar difficulties in institutional evaluation, both as a research and a consultancy programme. However, the public administrative training research project does also suggest that research can be done, and that it can contribute to consultancy processes.

\section{References}

B.B. Schaffer, Institutes for Administrative Training in Developing Countries - Some Emerging Themes, March 1971, p. 31.

B.B. Schaffer, The Problems of Using Training in Administrative Development, and Possible Alternatives, National Institute of Administration and Development, Lebanon, February 1972.

B.B. Schaffer, "Policy Decisions and Institutional Evaluation', IDS Discussion Paper 25, June 1973.

B.B. Schaffer (ed), Administrative Training and Development, Praeger, New York and Pall Mall Press, London, 1974.

B.B. Schaffer, "Policy Decisions and Institutional Evaluation", Development and Change, The Hague, 1974.

Work by Leys, and Leys and Stamp is referred to in the article, as also the theses completed by Wood, Cabatoff and Iglesias. Administrative Training and Development contains chapters by Schaffer, Allen, Leys, Stamp, Wood, Cabatoff, Mars.

The theses completed by Wood, Cabatoff and Iglesias are also referred to, as are reports by Jacobs and Schaffer, as further examples of the output. See also the Wamalwa and Ndegwa and other reports; and

Jake Jacobs and B.B. Schaffer, Training for Improved Performance by Public Services: An Assessment, Interregional Seminar on Mojor Administrative Reforms in Developing Countries, III, Pt. two, UN, 1973.

Robin Luckham, The Nigerian Military, Cambridge University Press, 1971.

R.W. Revans, Developing Effective Managers, Longmans, London, 1971. 